\title{
Corrigendum: Genetic variation in the prostate stem cell antigen gene PSCA confers susceptibility to urinary bladder cancer
}

Xifeng Wu, Yuanqing Ye, Lambertus A Kiemeney, Patrick Sulem, Thorunn Rafnar, Giuseppe Matullo, Daniela Seminara, Teruhiko Yoshida, Norihisa Saeki, Angeline S Andrew, Colin P Dinney, Bogdan Czerniak, Zuo-feng Zhang, Anne E Kiltie, D Timothy Bishop, Paolo Vineis, Stefano Porru, Frank Buntinx, Eliane Kellen, Maurice P Zeegers, Rajiv Kumar, Peter Rudnai, Eugene Gurzau, Kvetoslava Koppova, Jose Ignacio Mayordomo, Manuel Sanchez, Berta Saez, Annika Lindblom, Petra de Verdier, Gunnar Steineck, Gordon B Mills, Alan Schned, Shen-Chih Chang, Jie Lin, David W Chang, Katherine S Hale, Tadeusz Majewski, H Barton Grossman, Steinunn Thorlacius, Unnur Thorsteinsdottir, Katja K H Aben, J Alfred Witjes, Kari Stefansson, Christopher I Amos, Margaret R Karagas \& Jian Gu Nat. Genet. 41, 991-995 (2009); published online 2 August; corrected online 23 August 2009

In the version of this article initially published online, Simonetta Guarrera and Silvia Polidoro were inadvertently omitted from the author list, and an affiliation was omitted for Paolo Vineis. These errors have been corrected in all versions of this article.

\section{Erratum: Elucidating the role of 8q24 in colorectal cancer}

Olivier Harismendy \& Kelly A Frazer

Nat. Genet. 41, 868-869 (2009); published online 29 July; corrected after print 27 August 2009

In the version of this article initially published, there were two errors in the author contact information. The authors are at Scripps Genomic Medicine, Scripps Translational Science Institute and the Scripps Research Institute, La Jolla, California, USA; e-mail: kfrazer@scripps.edu or kafrazer@ucsd.edu. These errors have been corrected in the HTML and PDF versions of the article.

\section{Erratum: Genetic variant near IRS1 is associated with type 2 diabetes, insulin resistance and hyperinsulinemia}

Johan Rung, Stéphane Cauchi, Anders Albrechtsen, Lishuang Shen, Ghislain Rocheleau, Christine Cavalcanti-Proença, François Bacot, Beverley Balkau, Alexandre Belisle, Knut Borch-Johnsen, Guillaume Charpentier, Christian Dina, Emmanuelle Durand, Paul Elliott, Samy Hadjadj, Marjo-Riitta Järvelin, Jaana Laitinen, Torsten Lauritzen, Michel Marre, Alexander Mazur, David Meyre, Alexandre Montpetit, Charlotta Pisinger, Barry Posner, Pernille Poulsen, Anneli Pouta, Marc Prentki, Rasmus Ribel-Madsen, Aimo Ruokonen, Anelli Sandbaek, David Serre, Jean Tichet, Martine Vaxillaire, Jørgen F P Wojtaszewski, Allan Vaag, Torben Hansen, Constantin Polychronakos, Oluf Pedersen, Philippe Froguel \& Robert Sladek

Nat. Genet. 41, 1110-1115; published online 6 September; corrected online 13 September 2009

In the version of this article initially published online, there were errors in the e-mail addresses of two of the corresponding authors. The correct e-mail address for Robert Sladek is robert.sladek@mcgill.ca; the correct e-mail address for Philippe Froguel is philippe.froguel@good.ibl.fr. These errors have been corrected for all versions of this article.

\section{Erratum: Genome-wide association study identifies variants at CLU and PICALM associated with Alzheimer's disease}

Denise Harold, Richard Abraham, Paul Hollingworth, Rebecca Sims, Amy Gerrish, Marian L Hamshere, Jaspreet Singh Pahwa, Valentina Moskvina, Kimberley Dowzell, Amy Williams, Nicola Jones, Charlene Thomas, Alexandra Stretton, Angharad R Morgan, Simon Lovestone, John Powell, Petroula Proitsi, Michelle K Lupton, Carol Brayne, David C Rubinsztein, Michael Gill, Brian Lawlor, Aoibhinn Lynch, Kevin Morgan, Kristelle S Brown, Peter A Passmore, David Craig, Bernadette McGuinness, Stephen Todd, Clive Holmes, David Mann, A David Smith, Seth Love, Patrick G Kehoe, John Hardy, Simon Mead, Nick Fox, Martin Rossor, John Collinge, Wolfgang Maier, Frank Jessen, Britta Schürmann, Hendrik van den Bussche, Isabella Heuser, Johannes Kornhuber, Jens Wiltfang, Martin Dichgans, Lutz Frölich, Harald Hampel, Michael Hüll, Dan Rujescu, Alison M Goate, John S K Kauwe, Carlos Cruchaga, Petra Nowotny, John C Morris, Kevin Mayo, Kristel Sleegers, Karolien Bettens, Sebastiaan Engelborghs, Peter P De Deyn, Christine Van Broeckhoven, Gill Livingston, Nicholas J Bass, Hugh Gurling, Andrew McQuillin, Rhian Gwilliam, Panagiotis Deloukas, Ammar Al-Chalabi, Christopher E Shaw, Magda Tsolaki, Andrew B Singleton, Rita Guerreiro, Thomas W Mühleisen, Markus M Nöthen, Susanne Moebus, Karl-Heinz Jöckel, Norman Klopp, H-Erich Wichmann, Minerva M Carrasquillo, V Shane Pankratz, Steven G Younkin, Peter A Holmans, Michael O'Donovan, Michael J Owen \& Julie Williams Nat. Genet. 41, 1088-1093 (2009); published online 6 September; corrected after print 28 September 2009

In the version of this article initially published, the name of the first author of reference 12 was stated incorrectly in the reference list. The correct reference is: "Lambert, J.-C. et al. Genome-wide association study identifies variants at CLU and CR1 associated with Alzheimer's disease. Nat. Genet. advance online publication, doi:10.1038/ng.439 (6 September 2009).” The error has been corrected in the HTML and PDF versions of the article. 